\title{
Wood-bamboo Particleboard: Mechanical Properties
}

\author{
Aliane C. De Almeida, ${ }^{a}$ Victor A. De Araujo, ${ }^{\mathrm{b}, \mathrm{c}}$ Elen A. M. Morales, ${ }^{\mathrm{a}, \mathrm{b}}$ Maristela Gava, ${ }^{\mathrm{a}, \mathrm{b}}$ \\ Rafaele A. Munis, ${ }^{a}{ }^{\prime}$ osé N. Garcia, ${ }^{c}$ and Juliana Cortez-Barbosa ${ }^{a, b *}$ \\ Mechanical characteristics were evaluated of wood-bamboo-based \\ particleboard having the proportions of $100 \%$ wood and $0 \%$ bamboo, $75 \%$ \\ wood and $25 \%$ bamboo, and $50 \%$ wood and $50 \%$ bamboo. This \\ particleboard used Eucalyptus urophylla $\times$ grandis wood, Dendrocalamus \\ asper bamboo, and castor oil-based polyurethane resin. Through \\ destructive testing, the values of perpendicular tensile, static bending, \\ modulus of elasticity, and screw pullout strength in the top and face \\ surfaces were analyzed. For $0 \%, 25 \%$, and $50 \%$ bamboo the values were \\ 1.68 $\mathrm{MPa}, 1.37 \mathrm{MPa}$, and 1.4 MPa, respectively, for perpendicular tensile; \\ 15.2 MPa, 17.6 MPa, and 18.5 MPa, respectively, for static bending; 2466 \\ $\mathrm{MPa}, 2694 \mathrm{MPa}$, and $2922 \mathrm{MPa}$, respectively, for modulus of elasticity; \\ $1256 \mathrm{MPa}, 1922 \mathrm{MPa}$, and $1362 \mathrm{MPa}$, respectively, for screw pullout \\ strength in top; and $1392 \mathrm{MPa}, 1342 \mathrm{MPa}$, and $1414 \mathrm{MPa}$, respectively, \\ for screw pullout strength in face. These results were superior to those \\ presented by ABNT NBR 14810 (2013) and ANSI 208.1 (1999). After \\ performing a Tukey test at $5 \%$, the values for each treatment did not show \\ a significant difference among them.
}

Keywords: Eucalyptus urograndis; Dendrocalamus asper; Lignocellulosic Panel; Mechanical Properties

Contact information: a: Wood Industrial Engineering course, São Paulo State University, Rua Geraldo Alckmin, 519, Itapeva/SP, Brazil; b: Research Group on Development of Lignocellulosic Products (LIGNO), Rua Geraldo Alckmin, 519, Itapeva/SP, Brazil; c: Department of Forest Sciences, School of Agriculture Luiz de Queiroz, University of São Paulo, Avenida Pádua Dias, 11, Piracicaba/SP, Brazil;

*Corresponding author: jucortez@itapeva.unesp.br

\section{INTRODUCTION}

The knowledge regarding physical and mechanical characteristics of materials is extremely important, mainly for the determination of their application and correct use, and also for the design and manufacture of a structural element. Mechanical properties define the material's behavior during stressful conditions, and the relationship between elastic and plastic deformation, deriving the ratio of its maximum rupture.

Bamboo is a lignocellulosic material with low utilization worldwide with the exception of Asian and Latin-American regions according to Lobovikov et al. (2007) and Murad (2007). In the last few years, bamboo utilization in buildings has been studied and developed for European (Van der Lugt et al. 2006; Stamm 2008; Reynolds et al. 2016) and Brazilian scenarios (Bonilla et al. 2010; Melo et al. 2015; Zaia et al. 2015), revealing a recent world trend of sustainable raw material for construction employing wood.

However, the scientific field has presented a great potentiality for bamboos due to their rapid growth and positive mechanical characteristics. Bamboo has high elasticity and strength, which make it suitable for construction (Bhat et al. 2011), and this lignocellulosic material is a great potential alternative to wood (Gupta and Kumar 2008). 


\section{Wood-bamboo particleboard}

The study of mechanical properties is important to predict how materials behave under loads, when they are stress tested. These properties also make it possible to forecast how materials will run throughout their lifetime. In a comparison with natural composites, bamboo has high stiffness and strength due to its low density and high mechanical strength (Nurul Fazita et al. 2016). Bamboo particleboards are an economically viable, environmentally friendly, and sustainable alternative for the use of waste from bamboo processing (Zaia et al. 2015). The high consumption of wood can mean a high rate of deforestation worldwide, which can cause negative impacts on the environment. Due to this fact, there is an increasing interest in the production of particleboards from other biomass such as grass, straw, and agricultural residues (Zheng et al. 2007). Research dealing with the mechanical characteristics of these raw materials becomes vital to explore this alternative. In the manufacture of hybrid bamboo veneer waste and rubberwood particleboard, bamboo can be used as an alternative raw material to overcome the growing shortage of wood sources (Nurhazwani et al. 2016).

Nugroho and Ando (2000) studied the mechanical properties of bamboo boards, which revealed superior strength properties compared to commercial products, explained by their high density, resulting in a significant effect on the moduli of elasticity and rupture. To efficiently utilize the agricultural resources as an alternative source for composite panels, Lee et al. (2006) studied the variables to improve physical-mechanical properties of fiber-based on bamboo and bagasse. The study showed promising results for the moduli of elasticity and rupture. Jose and Beraldo (2010) tested the mechanical properties of particleboard made from Bambusa vulgaris bamboo and castor oil-based resin, and concluded that these panels achieved good behavior in thickness swelling. However, the mechanical properties of that study were unsatisfactory when compared to a popular structural panel for construction, oriented strand board.

Low-density particleboards generally present a higher sound absorption coefficient than medium-density ones; however, medium-density boards are more effective in insulation than low-density ones. The bamboo particleboards have promise for further development in acoustical purposes for construction, due to their good characteristics within the high-frequency range (Karlinasari et al. 2012).

In this context, this paper mechanically characterizes the wood-bamboo particleboard, presenting values for perpendicular tensile, static bending, modulus of elasticity, and screw pullout strength (of the face and top surfaces), as well as evaluating the bamboo insertion as a secondary material for medium-density particleboards.

\section{EXPERIMENTAL}

\section{Materials}

This study involved the utilization of sustainable materials to produce a woodbamboo particleboard: Eucalyptus urophylla $\times$ Eucalyptus grandis (eucalypt urograndis) wood species, Dendrocalamus asper bamboo species, and castor oil-based polyurethane resin (Plural Química, Cerquilho, Brazil); this two-component adhesive is based on castor oil-based polyol with isocyanate mixed with 4,4 '-diphenylmethane diisocyanate. 


\section{Methods}

Wood and bamboo particle production

Eucalyptus urophylla $\mathrm{x}$ grandis wood was collected in small dimensions (Fig. 1a), and these materials were hacked in a chipper. The length and thickness of these wood chips was reduced by milling. Particles smaller than 18 mesh were selected on a vibrating screen. These particles were separated and stored in a stove for $72 \mathrm{~h}$.

Bamboo from Dendrocalamus asper was collected as stems, which were sawn in the fiber-direction with a circular saw. With manual knife-assisted processing, the sawn stems were reduced to chips (Fig. 1b), which were milled and segregated on an 18-mesh vibrating screen. The obtained bamboo particles were dried for $72 \mathrm{~h}$.

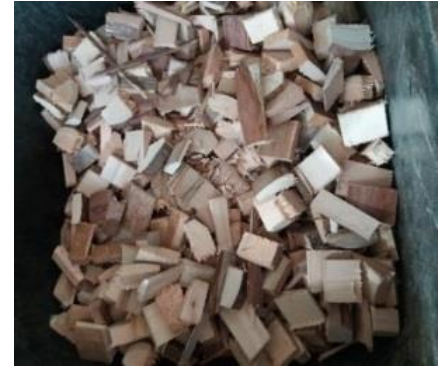

(a)

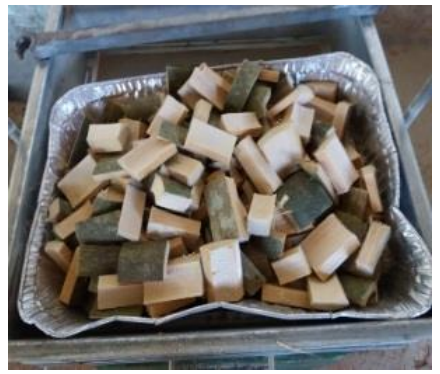

(b)

Fig. 1. Raw materials: (a) Eucalyptus urophylla $x$ grandis and (b) Dendrocalamus asper

\section{Wood-bamboo particleboard production}

Six particleboards were made with Eucalyptus urophylla $\times$ grandis hybrid wood (Placido's, Itapeva (SP), Brazil) and Dendrocalamus asper bamboo (Betania farm, Itapeva (SP), Brazil), glued with castor oil-based polyurethane resin (Plural Química, Cerquilho (SP), Brazil). Two panels by composition were produced for $100 \%$ wood and $0 \%$ bamboo, $75 \%$ wood and $25 \%$ bamboo, and $50 \%$ wood and $50 \%$ bamboo. Resin was manually mixed for each condition. The proportion for each panel was $90 \%$ of particles and $10 \%$ of resin. Each compound was individually mixed with a gluing machine for $10 \mathrm{~min}$. Panel formation included a rectilinear surface arrangement. These mats were pressured by a manual and cold mode with metal plates, and after, by a mechanical and hot mode $\left( \pm 160{ }^{\circ} \mathrm{C}\right)$ with a hydraulic press (PHH, Araraquara (SP), Brazil) at $\pm 160{ }^{\circ} \mathrm{C}$. The boards were pressed for $180 \mathrm{~s}$ with a release (degas) of $30 \mathrm{~s}$, and repeated two times. The process ended with a natural cooling in a conditioned room at $22{ }^{\circ} \mathrm{C}$ for $72 \mathrm{~h}$.

\section{Mechanical characteristics of produced wood-bamboo particleboard}

Tests of perpendicular tensile, static bending in moduli of elasticity and rupture, and screw pullout strength (in the top and face surfaces) were conducted according to the standard document ABNT NBR 14810-3 (2013), whereas the standard document ANSI 208.1 (1999) was used to comparison parameter for the results of screw pullout strength test. These tests were performed in the Laboratory of Mechanical Properties of Materials at UNESP, Campus of Itapeva, Brazil. In each particleboard type produced, according to the three observed traits, the specimens were extracted to perform these destructive tests, with respect to the prescribed amounts and sizes in the standard documents used. These tests were performed with a universal testing machine (EMIC, Instron Brasil, São José dos Pinhais (PR), Brazil) at 30 tons with speed control. 


\section{Perpendicular tensile determination}

Ten specimens of $50 \mathrm{~mm} \times 50 \mathrm{~mm}$ were extracted from the produced panels for each condition, totaling 30 of them. Specimens were conditioned to $12 \%$ of moisture content. Two metal claws to hold the tensile blocks, caliper ( $0.1 \mathrm{~mm}$ of accuracy), resin for MDF, table sander, clamps, and ten pairs of tensile wooden blocks were used in this test. Initially, the specimen surfaces were sanded to homogenize their faces. Specimens were glued together with the pairs of wooden blocks, and then, these sets were held in the clamps for the MDF-resin curing and impregnation (Fig. 2a). Then, through the claws, the specimens were ruptured.

\section{Static bending and modulus of elasticity determinations}

Ten rectangular specimens of $50 \mathrm{~mm} \times 50 \mathrm{~mm}$ and with the length of 20 times the thickness were extracted from the panels for each condition, totaling 30 specimens; they were conditioned to reach the equilibrium moisture. A cleaver with diameter of $30 \mathrm{~mm} \pm$ $5 \mathrm{~mm}$ and an analytical balance were also used. Thickness measurements were collected, and then, the ends of each specimen were placed on the supports of the universal testing machine (Fig. 2b), to apply the load to the center of each specimen until its rupture.

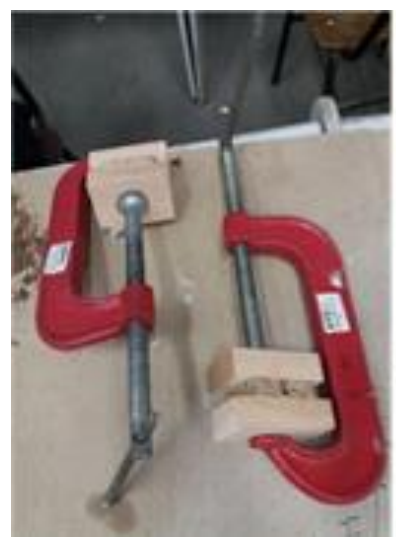

(a)

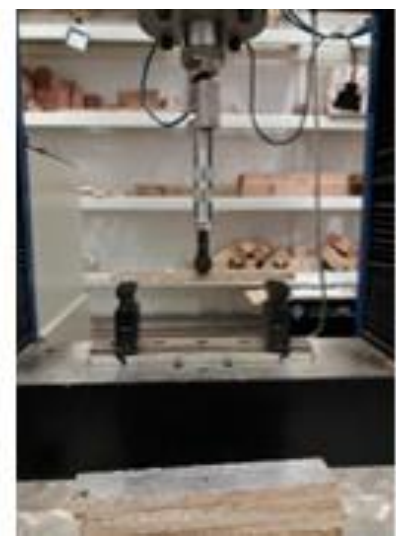

(b)

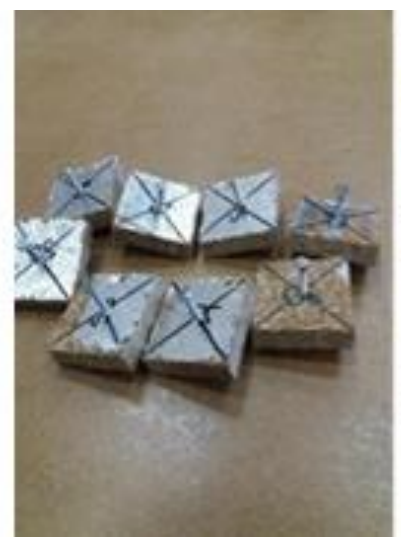

(c)



(d)

Fig. 2. (a) Specimen cold pressing, (b) static bending and modulus of elasticity test, (c) screw pullout strength in face specimens, and (d) in top specimens

\section{Screw pullout strength (face and top surfaces) determinations}

Twenty specimens of $50 \mathrm{~mm} \times 50 \mathrm{~mm}$ were extracted from the produced panels for each studied composition, totaling 60 specimens, half of which were directed to face testing (Fig. 2c) and the other ten specimens to top surface testing (Fig. 2d). Equipment used in this test was: screwdriver, portable drilling, drill $(2.7 \mathrm{~mm} \pm 0.1 \mathrm{~mm}$ in diameter), rudder to insertion of screws in the specimens, screw for wood (reference number 10), and accessories to be coupled to the specimens on the aforementioned testing machine. For the screw pullout strength test on the face surface, the specimens were drilled $(2.7 \mathrm{~mm} \pm 0.1$ $\mathrm{mm}$ ) to a depth of $15 \mathrm{~mm} \pm 0.5 \mathrm{~mm}$, centered on their surfaces. With a screwdriver, the screws were inserted at the drilled depth. For the screw pullout strength test of the top surface, the specimens endured the same process in the top position. The specimens (top and face) were fixed in the testing machine to obtain their results. 


\section{RESULTS AND DISCUSSION}

The obtained results for the experiments are graphically illustrated in Figs. 3 to 5, which demonstrated, respectively, the analysis of perpendicular tensile, static bending (to moduli of rupture and elasticity), and the screw pullout strength to surface (top and face). These values were subjected to statistical analysis using a Tukey test at a 5\%, by the software Sisvar 5.3 (Universidade Federal de Lavras, Lavras (MG), Brazil). Then, in these figures, the similarity among the characters $(\mathrm{A}, \mathrm{B}, \ldots)$ for each numerical result means that these values are statistically equivalent, according to Tukey test at $5 \%$.

The three conditions considered in Fig. 3 were very close, and there was not a significant difference among them, as determined by a Tukey test. All three treatment values were higher than their prescribed value according to ABNT NBR 14810-3 (2013), i.e., $0.4 \mathrm{MPa}$ for perpendicular tensile of medium-density particleboards. This difference among the obtained values and this normative value were related to the type of adhesive, natural or synthetic origin, which was natural-based for this study: castor oil-based polyurethane. In addition, Schwartz et al. (1968) reported that both the internal adhesion and modulus of rupture of engineered panel composites depend on the resin distribution. Moslemi (1974) and Kollmann et al. (1975) add that the high extractive content in wood can considerably reduce the resistance of internal adhesion, however, it can also provide a relative increase in the moisture. Melo et al. (2015) verified that for the gluing quality of wood-bamboo particleboards was not influenced by the different panel compositions.

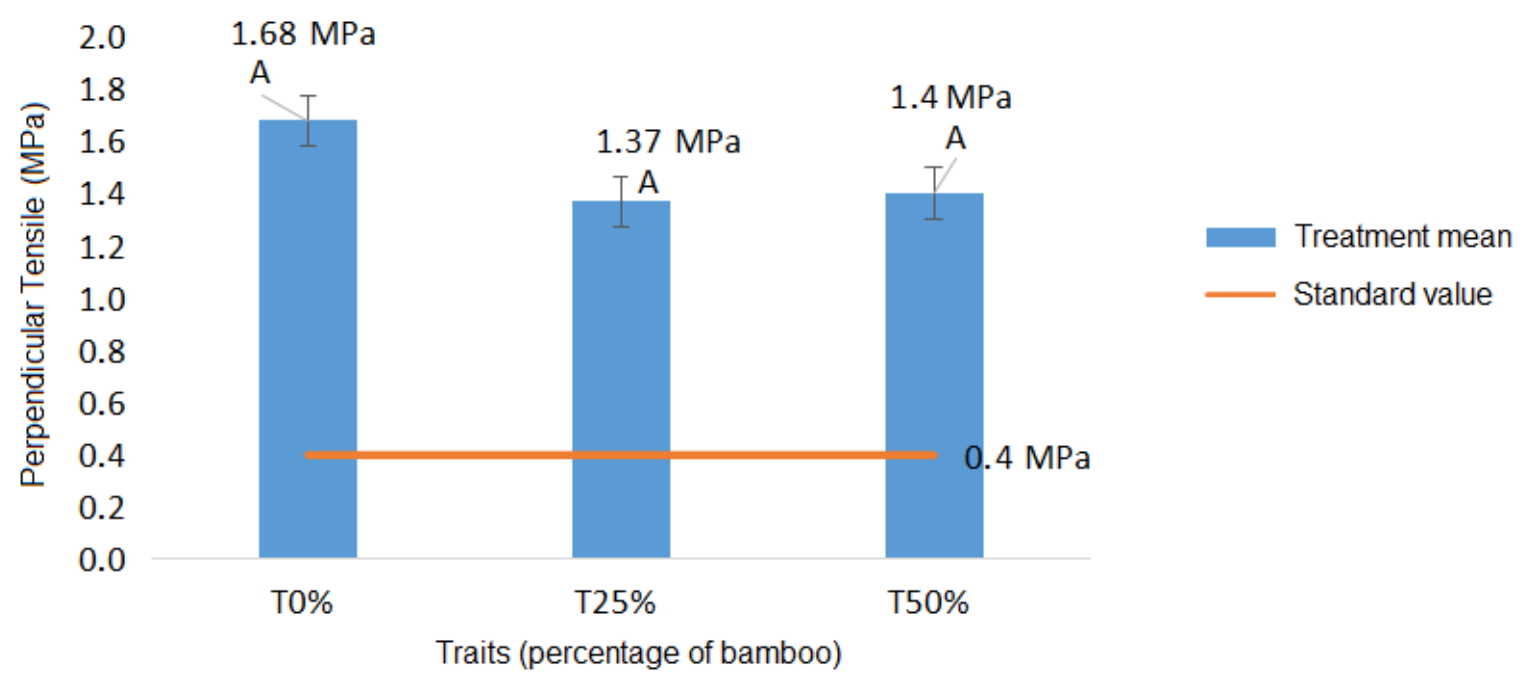

Fig. 3. Results of experimental analysis for perpendicular tensile strength

Melo et al. (2015) studied the physical and mechanical characteristics of the particleboards manufactured with different proportions of Eucalyptus grandis wood and Bambusa vulgaris bamboo (0\%, 25\%, 50\%, 75\%, and $100 \%$ bamboo addition), based on urea-formaldehyde resin. They verified that the quality of bonding, evaluated by internal bonding or perpendicular tensile strength from ABNT NBR 14810-3 (2013), was not influenced by the different wood-bamboo compositions, both for rupture as elasticity moduli.

Figure 4(a, b) shows that the values for each studied trait were higher than the value 
required by ABNT NBR 14810-3 (2013), which is $11 \mathrm{MPa}$ for the static bending of the modulus of rupture. In this scope, there was no significant difference among them, according to the Turkey test. Confirmation by a Tukey test determined there was no significant difference among them. Figure $4(a, b)$ showed that, in numerical values, there is an increasing trend in strengths according to the bamboo percentage increase, although the results have demonstrated a statistical equivalence.

Cabral et al. (2016) found the mean value of $14.89 \mathrm{MPa}$ for the static bending in modulus of rupture of medium-density particleboards based on Acacia mangium wood. Melo et al. (2015) verified the static bending for different wood and bamboo proportions $(0 \%, 25 \%, 50 \%, 75 \%$, and $100 \%)$ of lignocellulosic particleboards based on ureaformaldehyde resin. They stated that the panels fully-based on wood and also woodbamboo panels in 50\% of bamboo proportion complied with the requirements of $11 \mathrm{MPa}$ for the modulus of rupture and $1700 \mathrm{MPa}$ for the modulus of elasticity, both as stated by ANSI 208.1 (1999).

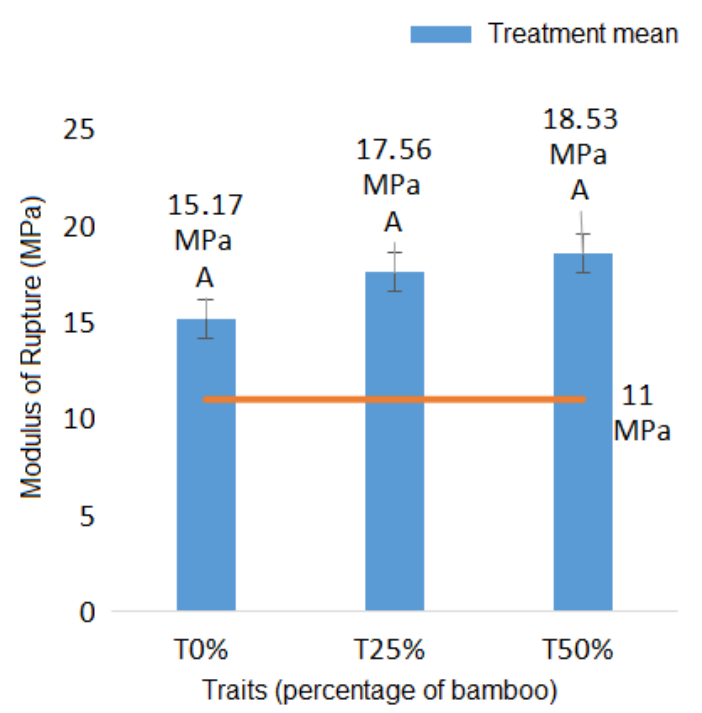

(a)

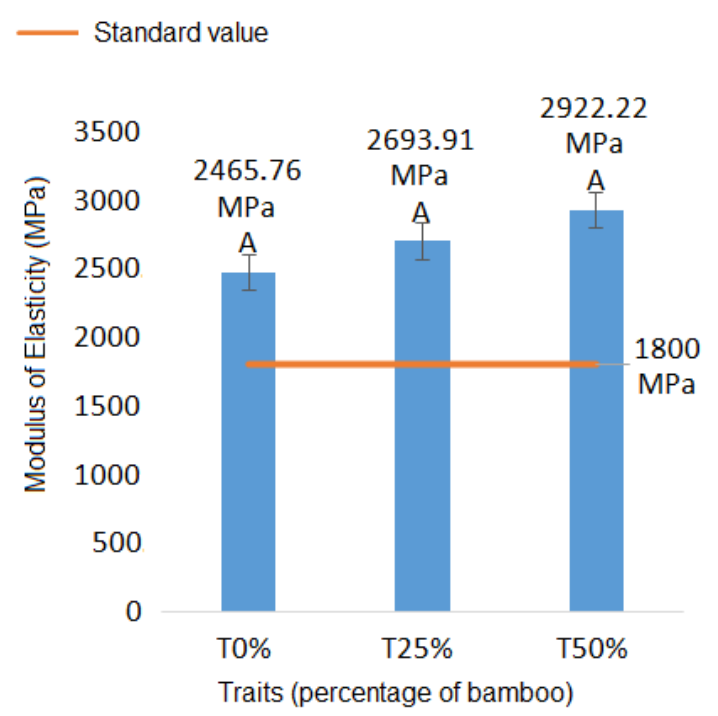

(b)

Fig. 4. Results of experimental analysis for static bending to moduli of (a) rupture and (b) elasticity

The standard ABNT NBR 14810-3 (2013) describes the properties of screw pullout strength (top and face) as a supplementary property for specific uses. The screw pullout strength were studied with the focus on the stimulus for the utilization of this new woodbamboo particleboard from the furniture industry, justifying the study of these particular properties showed in Fig. 5(a, b). Figure 5(a) shows the values for the screw pullout strength in the top surface for the three observed treatments $(0 \%, 25 \%$, and $50 \%$ bamboo). All of them were superior to those prescribed by ANSI 208.1 (1999), i.e., $800 \mathrm{~N}$ for screw pullout strength in the top surface. By a Tukey test at 5\% significance, these three traits did not indicate a significant difference among them.

When the bamboo was added in the panel, this same raw material contributed to particleboard resistance.

In addition, the difference of treatments, $25 \%$ and $50 \%$ of bamboo, could relate to 
the manual manufacture of studied particleboards in a laboratory scenario as well as the specimen location in each produced particleboard; these tested specimens were randomly collected in each produced particleboard (Fig. 5a). Figure 5(b) shows the values for the screw pullout strength in the face surface for the three observed treatments. These three traits obtained favorable values according to ANSI 208.1 (1999), i.e., $1000 \mathrm{~N}$ for screw pullout strength in the top surface. By a Tukey test at 5\%, these three traits did not reveal a significant difference among them.

Medium-density particleboard (MDP) is used by manufacturers of residential and commercial furniture, and therefore, the study of screw pullout strength is necessary, whereas this property analyzes the use of screws, which were often used as a connecting element in wooden furniture.

Based on the results, the authors propose future research with other wood-bamboo species and proportions to expand this scenario, and correlations to imply wood-bamboo particleboard use, e.g., sustainable and economic feasibilities.

Treatment mean

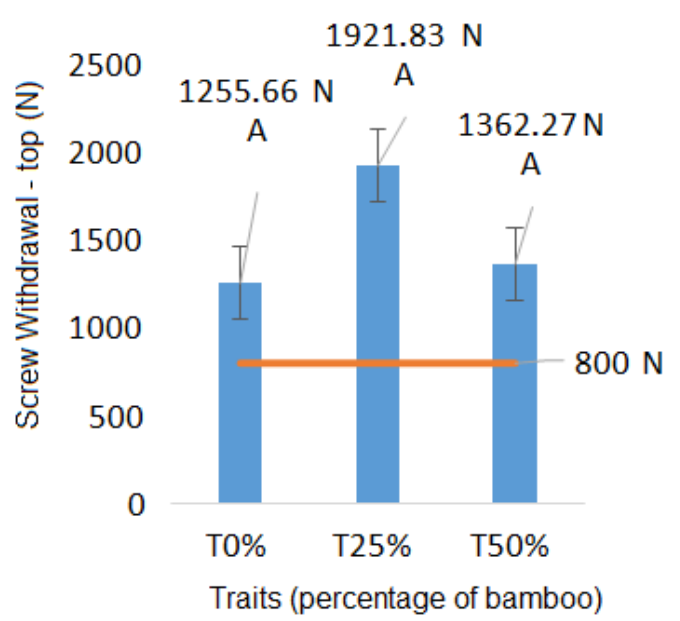

(a)

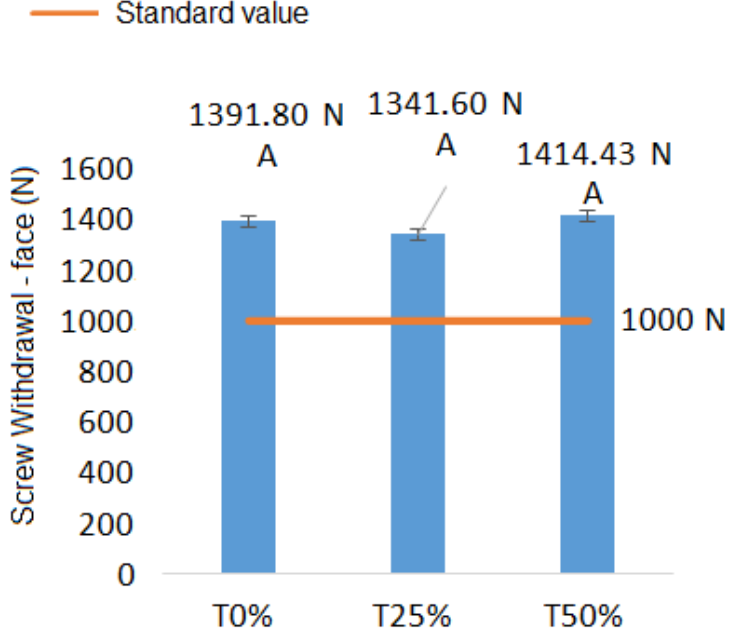

Traits (percentage of bamboo)

(b)

Fig. 5. Results of experimental analysis for screw pullout strength to surfaces, (a) top and (b) face

\section{CONCLUSIONS}

1. The study demonstrated that, for the resin and lignocellulosic materials, the insertion of bamboo in the proportions $25 \%$ and $50 \%$ promoted values higher than those from $100 \%$ wooden panels.

2. Bamboo has high potential for use in the furniture industry, especially to increase the mechanical properties of medium-density particleboards (MDP), which are currently produced only through wooden particles.

3. The bamboo utilization mixed with wood for the particleboard manufacture produced an efficient and natural-based panel, which contributed to the reduction of the timber consumption, valorizing another important renewable lignocellulosic material source. 


\section{ACKNOWLEDGEMENTS}

The authors are grateful for the support of São Paulo State University "Júlio de Mesquita Filho" (UNESP), Campus of Itapeva, for the permission to use its laboratories.

\section{REFERENCES CITED}

ABNT NBR 14810 (2013). "Painéis de partículas de média densidade - Parte 2: requisitos e métodos de ensaio [Sheet of particleboard - Part 2: Requirements and test methods]," Associação Brasileira de Normas Técnicas, Rio de Janeiro, Brazil.

ANSI 208.1 (1999). "Particleboard," American National Standard Institute, Gaithersburg, MD.

Bhat, I. U. H., Mustafa, M. T., Mohmod, A. L., and Abdul Khalil, H. P. S. (2011). "Spectroscopic, thermal, and anatomical characterization of cultivated bamboo (Gigantochloa spp.)," BioResources 6(2) 1752-1763. DOI: 10.15376/biores.6.2.17521763

Bonilla, S. H., Guarnetti, R. L., Almeida, C. M. V. B., and Giannetti, B. F. (2010). "Sustainability assessment of a giant bamboo plantation in Brazil: Exploring the influence of labour, time and space," J. Clean. Prod. 18(1), 83-91. DOI:

10.1016/j.jclepro.2009.07.012

Cabral, C. P. T., Pereira, B. L. C., Carvalho, D. M., Oliveira, A. C., Vital, B. R., Gomes, C. M., and Carneiro, A. C. O. (2016). "Efeito do tipo de chapa de partículas nas propriedades físicas e mecânicas [Effect of particleboard type in physical and mechanical properties]," Floresta e Ambiente 23(1), 118-123. DOI: 10.1590/21798087.030513

Gupta, A., and Kumar, A. (2008). "Potential of bamboo in sustainable development," Asia Pacific Bus. Rev. 4(3), 100-107. DOI: 10.1177/097324700800400312

Jose, F. J., and Beraldo, A. L. (2010). "Tableros de partículas de bambú (Bambusa vulgaris Schrad) y resina poliuretana a base de aceite de rícino (Ricinus communis L.) [Boards made of bamboo (Bambusa vulgaris Schrad) particles and castor oil-based polyurethane resin]," Ambiente Construído 10(4), 259-266, DOI: 10.1590/S167886212010000400018

Karlinasari, L., Hermawan, D., Maddu, A., Martianto, B., Lucky, I. K., Nugroho, N., and Hadi, Y. S. (2012). "Acoustical properties of particleboards made from Betung bamboo (Dendrocalamus asper) as building construction material," BioResources 7(4), 5700-5709. DOI: 10.15376/biores.7.4.5700-5709

Kollmann, F. F., Kuenzi, E. W., and Stamm, A. J. (1975). Principles of Wood Science and Technology: II Wood Based Materials, Springer-Verlag, Berlin/Heidelberg, Germany. DOI: 10.1007/978-3-642-87931-9_5

Lee, S., Shupe, T. F., and Hse, C. Y. (2006). "Mechanical and physical properties of agro-based fiberboard," Holz Roh. Werkst. 64(1), 74-79. DOI: 10.1007/s00107-0050062-z

Lobovikov, M., Ball, L., Guardia, M., and Russo, L. (2007). World Bamboo Resources: A Thematic Study Prepared in the Framework of the Global Forest Resources Assessment 2005, Book No. 18, FAO-UN, Rome, Italy. 
Melo, R. R., Stangerlin, D. M., de Sousa, A. P., Cademartori, P. H. G., and Schneid, E. (2015). "Propriedades físico-mecânicas de painéis aglomerados madeira-bambu [Physical mechanical properties of wood-bamboo particleboard]," Ciência Rural 45(1), 35-42. DOI: 10.1590/0103-8478cr20120970

Moslemi, A. A. (1974). Particleboard, Southern Illinois University Press, Carbondale, IL.

Murad, J. R. L. (2007). As Propriedades Físicas, Mecânicas e Mesoestrutural do Bambu Guadua weberbaueri do Acre [The Physical, Mechanical and Meso-structural Properties of the Bamboo Guadua Weberbaueri of Acre], Master's Thesis, Pontifícia Universidade Católica do Rio de Janeiro, Rio de Janeiro, Brazil.

Nugroho, N., and Ando, N. (2000). "Development of structural composite products made from bamboo I: Fundamental properties of bamboo zephyr board," Journal of Wood Science 46(1), 68-74. DOI: 10.1007/BF00779556

Nurhazwani, O., Jawaid, M., Paridah, M. T., Abdul , J. H., and Hamid, S. A. (2016). "Hybrid particleboard made from bamboo (Dendrocalamus asper) veneer waste and rubberwood (Hevea brasilienses)," BioResources 11(1), 306-323. DOI: 10.15376/biores.11.1.306-323

Nurul Fazita, M. R., Jayaraman, K., Bhattacharyya, D., Mohamad Haafiz, M. K., Saurabh, C. K., Hussin, M. H., and Khalil, A. H. P. S. (2016). "Green composites made of bamboo fabric and poly (lactic) acid for packaging applications," Materials 9(1), 435. DOI: 10.3390/ma9060435

Reynolds, T., Sharma, B., Harries, K., and Ramage, M. (2016). "Dowelled structural connections in laminated bamboo and timber," Composites Part B 90, 232-240. DOI: 10.1016/j.compositesb.2015.11.045

Schwartz, F. E., Anderson, R. L., and Kagder, A. G. (1968). "Resin distribution and how variations affect board quality," in: Proceedings of the Second Washington State University International Particleboard Symposium, Pullman, WA.

Stamm, J. (2008). "La evolución de los métodos constructivos en bambú," ["Evolution of building methods in bamboo"], in: Proceedings of the Congreso Mexicano de Bambu, CMB, Puebla, Mexico.

Van der Lugt, P., van den Dobbelsteen, A. A. J. F., and Janssen, J. J. A. (2006). “An environmental, economic and practical assessment of bamboo as building material for supporting structures," Constr. Build. Mater. 20(9), 648-656. DOI: 10.1016/j.conbuildmat.2005.02.023

Zaia, U. J., Cortez-Barbosa, J., Morales, E. A. M., Lahr, F. A. R., Nascimento, M. F., and De Araujo, V. A. (2015). "Production of particleboards with bamboo (Dendrocalamus giganteus) reinforcement," BioResources 10(1), 1424-1433. DOI: 10.15376/biores.10.1.1424-1433

Zheng, Y., Pan, Z., Zhang, R., Jenkins, B. M., and Blunk, S. (2007). 'Particleboard quality characteristics of saline jose tall wheatgrass and chemical treatment effect," Bioresource Technology 98, 1304-1310. DOI: 10.1016/j.biortech.2006.04.036

Article submitted: April 10, 2017; Peer review completed: July 4, 2017; Revised version received and accepted: August 1, 2017; Published: September 7, 2017.

DOI: 10.15376/biores.12.4.7784-7792 